\title{
ANÁLISE DA DINÂMICA DA COBERTURA VEGETAL NO ESTADO DE MATO GROSSO UTILIZANDO ÍNDICES DE VEGETAÇÃO DO SENSOR MODIS
}

\author{
Thales Vaz Penha ${ }^{(a)}$, Cristiane Nunes Francisco $^{(\mathrm{b})}$ \\ ${ }^{(a)}$ Divisão de Processamento de Imagens, Instituto Nacional de Pesquisas Espaciais. E-mail:thales.penha@inpe.br

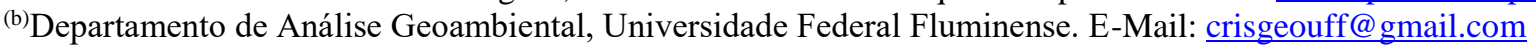

\author{
Eixo: GEOTECNOLOGIAS E MODELAGEM ESPACIAL EM GEOGRAFIA FÍSICA
}

\begin{abstract}
Resumo
As mudanças na dinâmica de uso e cobertura da terra no estado de Mato Grosso têm multiplas origens. Desde os anos 1970 com a introdução de novas técnicas e tecnologias no espaço agrário, impulsionadas pela expansão da atividade agropecuária, o processo de desmatamento tem se intensificado. $\mathrm{O}$ uso de dados e técnicas de sensoriamento remoto têm possibilitado estudos sobre a dinâmica da cobertura vegetal, o monitoramento do desmatamento e a análise das mudanças de uso e cobertura da terra. O presente estudo objetivou identificar as alterações da cobertura vegetal aplicando uma metodologia de detecção de mudanças e o uso de imagens MODIS com índices de vegetação NDVI e EVI para verificar as áreas desmatadas entre 2004 e 2014 na Amazônia matogrossense. Os resultados dos mapeamentos foram considerados satisfatórios com exatidão global (94\% para NDVI e $82 \%$ para EVI) e índice Kappa (0,83 a NDVI e 0,58 a EVI).
\end{abstract}

Palavras-chave: MODIS; índices de vegetação; desmatamento; Amazônia.

\section{Introdução}

O Estado do Mato Grosso é o terceiro maior estado brasileiro em extensão territorial, que teve seu processo de expansão econômica iniciado de forma mais expressiva a partir de sua divisão territorial e administrativa (SEMA/MT, 2009). Segundo Silva (2009), as macropolíticas econômicas do governo federal no período de 1970 tiveram impactos diretos sobre Mato Grosso e particularmente sobre o sudeste do estado. Um novo ciclo de transformações no território mato-grossense, impulsionado pelos adventos da Revolução Verde e pelos planos de desenvolvimento da região, provocou não apenas a modernização do espaço agrário e um crescimento econômico acelerado do estado. Foram consolidadas duas novas frentes em Mato Grosso: a frente de desflorestamento e a frente de expansão da fronteira agrícola a partir da pecuária e da agricultura de soja (Becker, 2007).

O desmatamento é um processo que se inicia com a floresta intacta e termina com a conversão completa da floresta original em outras coberturas INPE (2008). Até meados de 2007, cerca de 175 mil $\mathrm{Km}^{2}$ de floresta e $150 \mathrm{mil} \mathrm{Km}^{2}$ de cerrado foram desmatados em Mato Grosso, o que representa, respectivamente, cerca de $35 \%$ e $42 \%$ da área de cobertura vegetal original mato-grossense. Apesar da expressiva diminuição do desmatamento nos últimos cinco anos, o Mato Grosso ainda encabeça o 
ranking dos estados campeões do desmatamento, sendo responsável por mais de $30 \%$ do desmatamento registrado na Amazônia brasileira. (SEMA/MT, 2009).

Estudos como de Morton et al. (2004) e Anderson et al. (2005) investigaram a questão do desmatamento em Mato Grosso utilizando técnicas de sensoriamento remoto com uso do sensor MODIS (Moderate Resolution Imaging Spectroradiometer). Em geral, os trabalhos que utilizam processamento digital na detecção de mudanças baseiam-se no pressuposto de que as mudanças da cobertura da terra, tanto naturais quanto de origem antrópica, produzem variações detectáveis na resposta espectral do alvo estudado (Anderson, 2005). Detectar mudanças é o processo de identificar alterações no estado de um objeto ou fenômeno observando-o em momentos diferentes (Singh, 1989), que envolve a quantificação dos efeitos temporais ao utilizar conjuntos de dados multi-temporais de sensores remotos.

Um grande número de técnicas tem sido desenvolvido para a detecção de mudança em imagem multiespectrais. A obtenção de informações satisfatórias sobre mudanças deve abranger: variação de área de mudança, distribuição espacial dos tipos alterados, trajetórias de tipos de cobertura da terra, e avaliação da precisão da detecção de mudança (Lu et al., 2004). As abordagens de detecção de mudança são caracterizadas em dois grandes grupos: mudanças bi-temporal, que utiliza duas imagens em datas distintas, e a análise trajetória temporal (Jyania et al., 2008).

O emprego de índices de vegetação tem sido frequente em estudos desta natureza. O NDVI (Normalized Diference Vegetation Index - Índice de Vegetação da Diferença Normalizada), proposto por Rouse et al. (1974), é um dos mais aplicados e tem sido explorado em estudos climáticos e de culturas agrícolas e florestais (Ponzoni et al., 2012). Enquanto o EVI (Enhanced Vegetation Index - em português também), desenvolvido por Huete et al. (1997), corresponde a uma variação do NDVI para corrigir as influências da atmosfera e do solo ao utilizar a banda do azul, otimizando o sinal da vegetação com a melhoria da sensibilidade em regiões com maior densidade de biomassa, e aprimorando o monitoramento da vegetação através de uma ligação do sinal de fundo do dossel e da redução das influências atmosféricas (Coura, 2007).

O sensor MODIS tem subsidiado pesquisas, fornecendo imagens diárias das condições da superfície terrestre. O produto MOD13, de nível 3 na hierarquia de processamento, traz dois índices de vegetação, o NDVI e o EVI, gerados em composições quinzenais, mensais e anuais, nas resoluções de 250 m, 500 m e 1 km (Rosemback, 2007). Essas composições têm como principais objetivos minimizar a interferência de nuvens, discriminar com precisão as variações interanuais da vegetação e maximizar a cobertura global e temporal na resolução espacial mais fina possível.

O presente estudo tem como objetivo a aplicação de técnica de detecção de mudança, com uso dos índices de vegetação gerados por imagens do sensor MODIS, para verificar a dinâmica da cobertura 


\section{OS DESAFIOS DA GEOGRAFIA FÍSICA NA FRONTEIRA DO CONHECIMENTO \\ Instituto de Geociências - Unicamp \\ Campinas - SP \\ 28 de Junho à 02 de Julho de 2017}

vegetal na região da Amazônia do estado de Mato Grosso, entre os anos de 2004 e 2014, bem como fazer avaliação comparativa entre os índices de vegetação utilizados.

\section{Materiais e Métodos}

A definição do recorte espacial da Amazônia mato-grossense refere-se ao mapeamento de biomas do Brasil propostos por IBGE (Instituto Brasileiro de Geografia e Estatistica) e MMA (Ministério do Meio Ambiente) na escala 1:5.000.000 (Figura 01). A aquisição das imagens MODIS foi realizada através do portal Banco de Produtos MODIS da Empresa Brasileira de Pesquisa Agropecuária Informática Agropecuária (EMBRAPA - CNPTIA).

A seleção dos produtos MOD13, disponibilizados na forma de mosaico de 16 dias e resolução espacial de 250 metros, foi baseada no artigo de Marcuzzo et al. (2010) que realizaram um estudo da série histórica de precipitação pluviométrica para a Amazônia mato-grossense. Tendo em vista que o período de estiagem para a região que compreende os meses de junho a agosto, sendo o mês de julho o menos chuvoso, adotou-se como critério de escolha das imagens MODIS índices de vegetação NDVI e EVI da segunda quinzena de julho dos anos de 2004 e 2014. Ademais, a escolha pelo período de estiagem se deve a baixa incidência de nuvens, diminuindo consideravelmente as chances de interferências e ruídos atmosféricos, bem como as influências na resposta de reflectância da vegetação, garantindo assim a qualidade dos produtos MOD13 NDVI e EVI.

Além disso, outras duas fontes de dados matriciais fundamentais para este estudo foram os mosaicos OLI-Landsat. O arquivo do ano de 2014 foi adquirido no Portal GeoNetwork da Agência Nacional das Águas (ANA), enquanto o mosaico de 2004 que foi gerado pelo autor a partir de 30 cenas Landsat ETM+ PanMosaics (1999-2003) adquiridos do sítio Earth Explorer - USGS (U.S. Geological Survey). Os demais dados utilizados neste estudo foram obtidos da base de dados geográficos do MMA e IBGE.

A metodologia empregada neste estudo consistiu em uma análise comparativa entre os mosaicos e as imagens MODIS NDVI e EVI dos anos 2004 e 2014. Explorando as áreas com cobertura vegetal natural e áreas antropizadas, foram testados e calibrados diferentes valores de NDVI e EVI de forma heurística pelo usuário, testando interativamente limiares para a discriminação adequada das classes, conforme Francisco e Almeida (2012).

Após essa etapa, aferiram-se os valores dos índices NDVI e EVI que representassem as classes: floresta e não floresta. Em seguida, as imagens MODIS NDVI e EVI dos anos 2004 e 2014 foram classificadas para as classes floresta e não floresta de acordo com os valores definidos nos testes. 


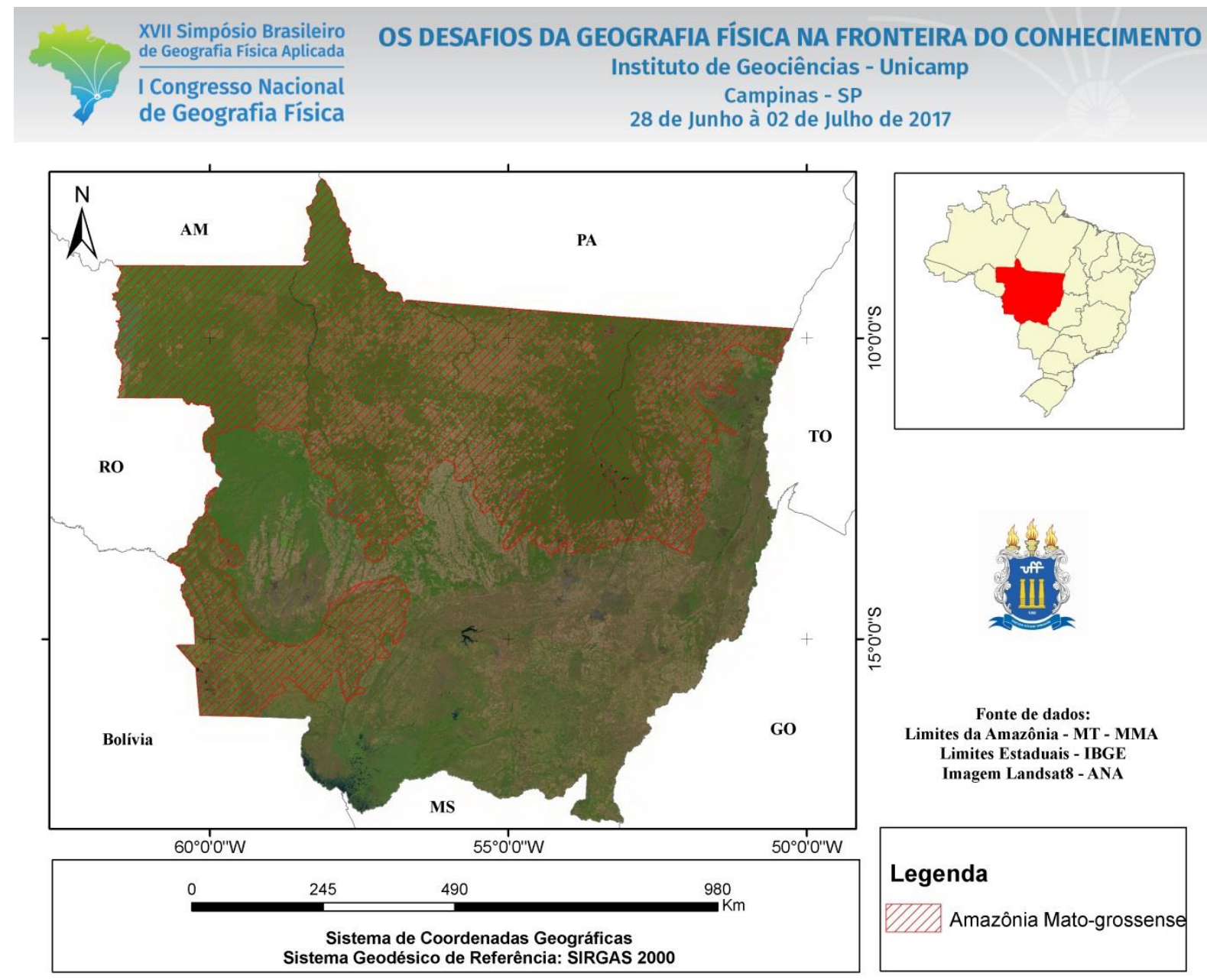

Figura 1: Mapa de localização da área de estudo: Amazônia mato-grossense.

A etapa seguinte consistiu em verificar as mudanças da cobertura vegetal através de um cálculo aritmético da diferença entre os mapas 2004 e 2014, conforme as equações (3) e (4). As áreas correspondentes às classes floresta e não floresta foram reclassificadas para três classes após a subtração dos pixels, denominadas como: classe 1, incremento de vegetação, pois indica um aumento dos índices de vegetação de 2004 para 2014; classe 2, área de vegetação não alterada, pois valores de NDVI e EVI não variaram; e classe 3, decremento de vegetação, pois houve diminuição do índice de vegetação de 2004 para 2014.

A classe 1, incremento de vegetação, como indicado pelos índices de vegetação está relacionada as áreas com provável ganho de vegetação. A classe 2, decremento de vegetação, está relacionada as áreas com provável perda de vegetação (desmatamento).

DIF_NDVI $2004 / 2014=$ Mapa_NDVI $2004-$ Mapa_NDVI ${ }_{2014}$

DIF_EVI $2004 / 2014=$ Mapa_EVI $2004-$ Mapa_EVI 2014

Onde: NDVI2004 corresponde ao mapa MOD13 NDVI do ano de 2004; NDVI2014 corresponde ao mapa MOD13 NDVI do ano de 2014; EVI2004 corresponde ao mapa MOD13 EVI do ano de 2004; EVI2014 corresponde ao mapa MOD13 EVI do ano de 2014. 
Para quantificar as áreas de decremento e incremento de vegetação, realizou-se um cálculo de área para cada classe. Após análise foram excluídas do cálculo as áreas menores que $0,25 \mathrm{~km}^{2}$ ou $25 \mathrm{ha}$, correspondentes a quatro pixels da imagem MODIS, visto que estas pequenas áreas podem não representar uma mudança na cobertura vegetal, mas sim um erro em função da resolução espacial das imagens utilizadas.

Por fim, realizou-se uma validação dos resultados dos mapeamentos. Foram sorteados pontos aleatórios e como referência utilizou-se os mosaicos das imagens Landsat. Para definição do número de amostras foram adotados os preceitos de Congalton (2009) que define que para mapas com 1 milhão de acres e x classes, é necessária a coleta de no mínimo de 50 amostras por classe. Foi gerado um total de 900 amostras, para o mapa de mudanças de cobertura vegetal gerado a partir do NDVI e 1.355 amostras, para o mapa de mudanças de cobertura vegetal gerado a partir do EVI. Em seguida, foi a gerada a matriz de confusão e foram calculados os índices de acurácia (exatidão do produtor, exatidão do consumidor, exatidão global e índice Kappa).

\section{Resultados e Discussão}

A Figura 2 apresenta o mapa das mudanças da cobertura vegetal gerado pela reclassificação do índice NDVI da Amazônia mato-grossense. Nota-se que não há uma concentração espacial das manchas de mudanças da cobertura vegetal, encontrando-se distribuídas pela área de estudo. No entanto, as maiores predominam no noroeste do estado, sendo que o decremento de vegetação ocorreu principalmente nas bordas de áreas já desmatadas, enquanto as áreas de incremento predominaram no interior das áreas de floresta.

A Tabela I apresenta a área das classes floresta e não floresta, definidas pelo limiar testado (valor de NDVI correspondente a 0,76 ) para distinguir a área com floresta amazônica das demais classes de cobertura (não floresta). Nota-se que houve perda de cerca de 4,77\% da área da floresta entre 2004 e 2014.

Tabela I: Área das classes de cobertura vegetal de acordo com NDVI.

\begin{tabular}{|c|c|c|c|c|c|}
\hline Classe & $\begin{array}{c}\left.\text { Área (mil } \mathbf{K m}^{2}\right) \\
\mathbf{2 0 0 4}\end{array}$ & $\begin{array}{c}\text { Área (\%) } \\
\mathbf{2 0 0 4}\end{array}$ & $\begin{array}{c}\text { Área }\left(\mathbf{m i l ~ K m}^{2}\right) \\
\mathbf{2 0 1 4}\end{array}$ & $\begin{array}{c}\text { Área (\%) } \\
\mathbf{2 0 1 4}\end{array}$ & $\begin{array}{c}\text { Dif 2004-2014 } \\
(\mathbf{\%})\end{array}$ \\
\hline Floresta & 315,82 & 63,53 & 292,13 & 58,76 & $-4,77$ \\
\hline Não floresta & 181,25 & 36,46 & 204,96 & 41,23 & $+4,77$ \\
\hline
\end{tabular}




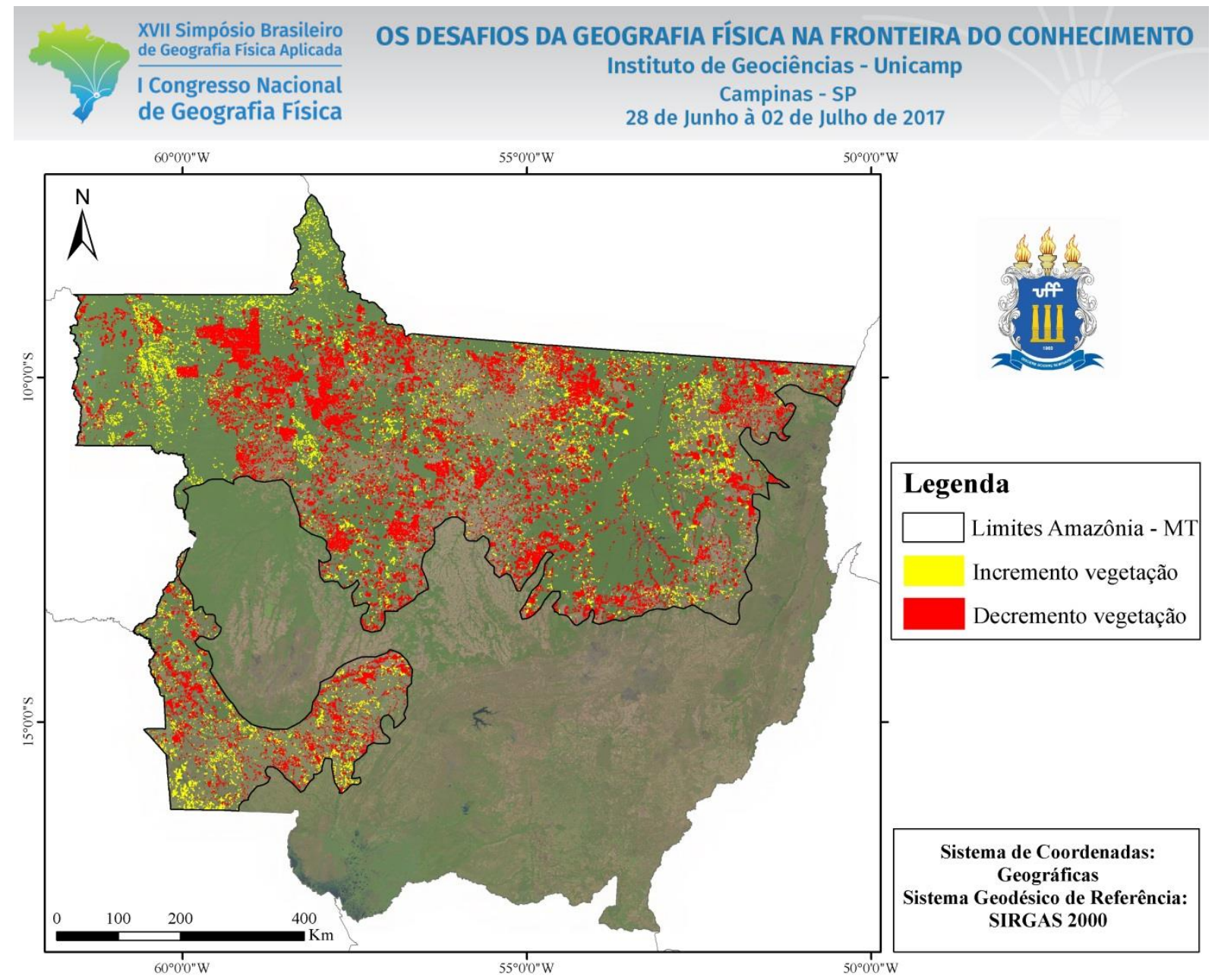

Figura 2: Mapa de mudança da cobertura vegetal 2004-2014 de acordo com NDVI.

O resultado do mapeamento de mudança da cobertura vegetal, de acordo com o NDVI, apresenta-se na Tabela II. Observa-se que no período de 2004 a 2014 houve um decréscimo de vegetação da ordem de 6,59\% da área total da Amazônia mato-grossense e um pequeno aumento de áreas com vegetação, cerca de $1,66 \%$ do total, correspondendo a uma perda equivalente a aproximadamente 4,32 milhões campos de futebol.

Tabela II: Área das classes de mudança da cobertura vegetal de acordo com NDVI.

\begin{tabular}{|c|c|c|}
\hline Classe & Área (mil $\left.\mathbf{K m}^{\mathbf{2}}\right)$ & Área (\%) \\
\hline Incremento de vegetação & 7,77 & 1,66 \\
\hline Vegetação não alterada & 429,40 & 91,74 \\
\hline Decremento de vegetação & 30,85 & 6,59 \\
\hline
\end{tabular}

A Figura 3 apresenta o mapa das mudanças da cobertura vegetal gerado pela reclassificação do índice EVI da Amazônia mato-grossense. Verifica-se que o padrão das mudanças é semelhante ao anterior, no entanto é perceptível que a área com mudanças da cobertura da terra é maior que a do mapa anterior. 


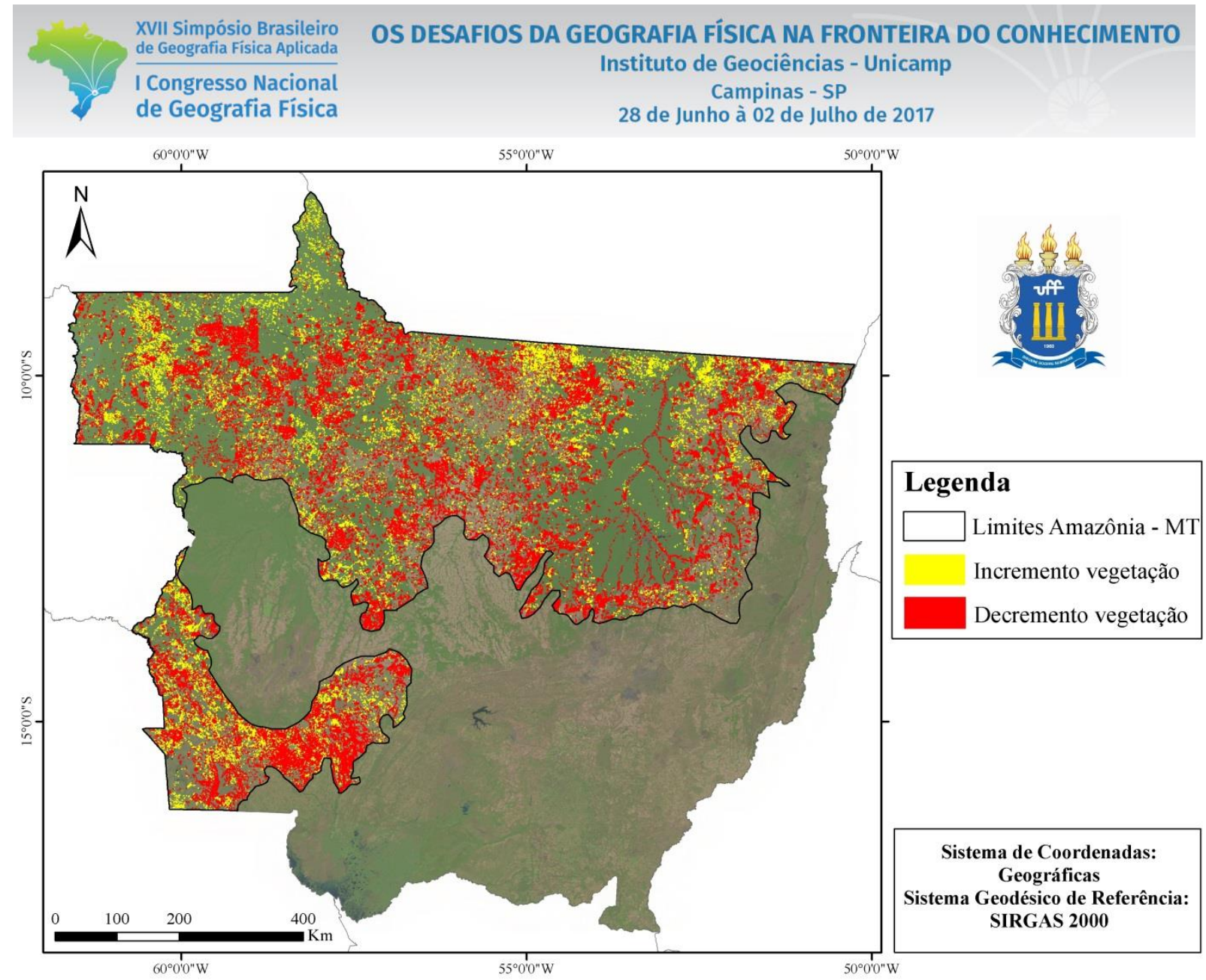

Figura 3: Mapa de mudança da cobertura vegetal 2004-2014 de acordo com EVI.

A Tabela III apresenta a área das classes floresta e não floresta, definidas pelo limiar testado (valor de EVI correspondente a 0,42) para distinguir a área com floresta amazônica das demais classes de cobertura (não floresta). Nota-se que houve perda de cerca de 6\% da área da floresta entre 2004 e 2014.

Tabela III: Área das classes de cobertura vegetal de acordo com EVI.

\begin{tabular}{|c|c|c|c|c|c|}
\hline Classe & $\begin{array}{c}\text { Área (mil Km} \\
\mathbf{2 0 0 4}\end{array}$ & $\begin{array}{c}\text { Área (\%) } \\
\mathbf{2 0 0 4}\end{array}$ & $\begin{array}{c}\text { Área (mil Km } \\
\mathbf{2 0 1 4}\end{array}$ & $\begin{array}{c}\text { Área (\%) } \\
\mathbf{2 0 1 4}\end{array}$ & $\begin{array}{c}\text { Dif 2004-2014 } \\
(\mathbf{\%})\end{array}$ \\
\hline Floresta & 330,87 & 66,56 & 301,00 & 60,55 & -6.01 \\
\hline Não floresta & 166,20 & 33,43 & 196,07 & 39,44 & +6.01 \\
\hline
\end{tabular}

A classe floresta do EVI possui 3\% a mais de áreas detectadas em 2004 e 2\% a mais de áreas florestadas em 2014 em relação às áreas identificadas pelo NDVI. Em relação à perda de vegetação da classe floresta de 2004 a 2014 segundo o EVI, houve uma supressão de 6\% de áreas vegetadas, enquanto para o mesmo período segundo o NDVI a redução foi de $4.77 \%$.

Constatou-se ao comparar as áreas mapeadas como floresta que, em alguns casos, correspondiam a áreas de cultivos agrícolas ou pastagem na imagem de referência Landsat. Isto pode ser justificado 
pelo fato do índice de vegetação EVI ser mais sensível à detecção de biomassa e, portanto, diferentes tipos de vegetação apresentam EVI semelhante aos de vegetação densa.

O resultado do mapeamento de mudança da cobertura vegetal, de acordo com o EVI, apresenta-se na Tabela IV. Observa-se que no período de 2004 a 2014 houve um decréscimo de vegetação da ordem de $8,72 \%$ da área total da Amazônia mato-grossense e um pequeno aumento de áreas com vegetação, cerca de $2,97 \%$ do total, correspondendo a uma perda equivalente a aproximadamente 5,62 milhões campos de futebol.

Tabela IV: Área das classes de mudança da cobertura vegetal de acordo com EVI.

\begin{tabular}{|c|c|c|}
\hline Classe & Área $\left(\mathbf{K m}^{\mathbf{2}} \mathbf{)}\right.$ & Área (\%) \\
\hline Incremento de vegetação & 13,69 & 2,97 \\
\hline Vegetação não alterada & 406,65 & 88,31 \\
\hline Decremento de vegetação & 40,09 & 8,72 \\
\hline
\end{tabular}

Verifica-se que o EVI identifica mais áreas da cobertura vegetal alteradas de 2004 a 2014 do que o NDVI seja por acréscimo ou decréscimo de vegetação, isto colabora para análise de que o EVI é um índice mais sensível à variação de biomassa. Além disso, muitas das áreas identificadas pelo EVI como vegetação (floresta) podem estar superestimadas ou misturadas com outras classes de uso do solo. Em contrapartida, o NDVI possui uma rápida saturação a partir de um determinado valor, tornando-se pouco sensível à detecção de variações no aumento da biomassa vegetal.

A Tabela $\mathrm{V}$ apresenta a matriz de confusão do mapa de mudanças na cobertura vegetal gerado pelo NDVI. Verifica-se que a exatidão global correspondeu a 94\% e o índice Kappa 0,83, correspondendo a índices elevados que podem ser classificados como muito bom a excelente de acordo com Congalton (1991). Os erros de omissão e comissão foram baixos, com índices de exatidão do produtor variando entre 0,94 a 0,92 e do consumidor entre 0,97 a 0,82 , sendo que os menores valores corresponderam à classe incremento de vegetação. 
XVII Simpósio Brasileiro

de Geografia Fisica Aplicada

I Congresso Nacional

de Geografia Física

\section{OS DESAFIOS DA GEOGRAFIA FÍSICA NA FRONTEIRA DO CONHECIMENTO \\ Instituto de Geociências - Unicamp \\ Campinas - SP \\ 28 de Junho à 02 de Julho de 2017}

Tabela V: Matriz de confusão do mapa de mudanças da cobertura vegetal gerado pelo NDVI.

\begin{tabular}{|c|c|c|c|c|}
\hline \multirow{2}{*}{\multicolumn{2}{|c|}{ Classes }} & \multicolumn{2}{|c|}{ Amostras de referência } & \multirow{2}{*}{$\begin{array}{c}\text { Total } \\
\text { classificadas }\end{array}$} \\
\hline & & Decremento & Incremento & \\
\hline \multirow{2}{*}{ 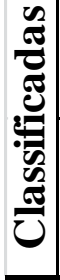 } & Decremento de Vegetação & 661 & 17 & 678 \\
\hline & Incremento de Vegetação & 39 & 183 & 222 \\
\hline & Total de amostras & 700 & 200 & 900 \\
\hline & Validação & Decremento & Incremento & Exatidão Global \\
\hline & Exatidão do produtor & 0.94 & 0.92 & \multirow{2}{*}{$94 \%$} \\
\hline & Exatidão do consumidor & 0.97 & 0.82 & \\
\hline & Índice Kappa & \multicolumn{3}{|c|}{0.83} \\
\hline
\end{tabular}

Verifica-se na Tabela VI que os índices do mapa de mudanças na cobertura vegetal gerado pelo EVI alcançaram resultados inferiores, principalmente, referentes a classe de incremento, o que ocasionou em exatidão global correspondendo a $82 \%$ e índice Kappa $58 \%$, considerado como concordância boa ou moderada, de acordo com Congalton (1991). Os erros de omissão e comissão foram mais altos, com índices de exatidão do produtor variando entre 0,92 a 0,83 e do consumidor entre 0,80 a 0,63 , sendo que os menores valores corresponderam à classe de incremento de vegetação.

Tabela VI: Matriz de confusão do mapa de mudanças da cobertura vegetal gerado pelo EVI.

\begin{tabular}{|c|c|c|c|c|}
\hline \multirow{2}{*}{\multicolumn{2}{|c|}{ Classes }} & \multicolumn{2}{|c|}{ Amostras de referência } & \multirow[b]{2}{*}{$\begin{array}{c}\text { Total } \\
\text { classificadas }\end{array}$} \\
\hline & & Decremento & Incremento & \\
\hline \multirow{2}{*}{ 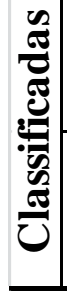 } & Decremento de Vegetação & 831 & 169 & 1000 \\
\hline & Incremento de Vegetação & 72 & 283 & 355 \\
\hline & Total de amostras & 903 & 452 & 1355 \\
\hline & Validação & Decremento & Incremento & Exatidão Global \\
\hline & Exatidão do produtor & 0.92 & 0.63 & \multirow{2}{*}{$82 \%$} \\
\hline & Exatidão do consumidor & 0.83 & 0.80 & \\
\hline \multicolumn{2}{|r|}{ Índice Kappa } & \multicolumn{3}{|c|}{0.58} \\
\hline
\end{tabular}




\section{Conclusões}

Os mapeamentos de mudança na cobertura vegetal da Amazônia mato-grossense do ano de 2004 a 2014 derivados das imagens MODIS NDVI e EVI apresentaram resultados satisfatórios. Ambos os mapeamentos obtiveram índice Kappa e índice de exatidão global elevados, com destaque para o mapeamento com o índice de vegetação NDVI que segundo a validação foi superior ao EVI. No entanto, os resultados dos dois mapeamentos são muito próximos. No incremento de vegetação a diferença foi de $1 \%$ e decremento $2 \%$.

As imagens MODIS do produto MOD13 com os índices de vegetação NDVI e EVI apresentam grande potencial para análises temporais sobre o estado da cobertura vegetal O NDVI apresentou maior índice de acurácia do que o EVI, contudo, é importante salientar que os índices podem ter superestimado ou subestimando áreas mapeadas. A mistura espectral dos alvos é outro limitante, porém este é um erro inerente à escala de mapeamento e da resolução espacial do sensor MODIS.

Os mapas gerados com decremento e incremento de vegetação, indicando áreas desmatadas e áreas com possível regeneração da vegetação, são resultados que podem subsidiar tomadas de decisões e a gestão de políticas públicas de combate ao desmatamento. Apesar de não apresentar muito detalhamento, estes resultados indicam os locais mais críticos que devem ser tratados como prioritários para a gestão do território.

\section{Referências Bibliográficas}

ANDERSON, L. O. Classificação e monitoramento da cobertura vegetal do Estado de Mato Grosso utilizando dados multitemporais do sensor MODIS. Dissertação (Mestrado em Sensoriamento Remoto) - Instituto Nacional de Pesquisas Espaciais. São José dos Campos - SP, 2005.

ANDERSON, L. O.; SHIMABUKURO, Y. E.; DEFRIES, R. S.; MORTON, D. Assessment of Deforestation in Near Real Time Over the Brazilian Amazon Using Multitemporal Fraction Images Derived From Terra MODIS. IEEE Geoscience and Remote Sensing Letters, vol. 2, no. 3, 2005.

BECKER, B. K. A Amazônia e a política ambiental brasileira. In: SANTOS, M. \& BECKER, B. K. (org.). Território, Territórios: ensaios sobre o ordenamento territorial. Rio de Janeiro: Lamparina, 2007. $3^{\circ} \mathrm{ed}$, pg. 22-40.

CONGALTON, R. G. A review of assessing the accuracy of remotely sensed data. Remote sensing of envinronment, n.37, p.35-46, 1991.

CONGALTON, R. G; GREEN, K. Assessing the accuracy of remotely sensed data: principles and practices. 2 ed. United States of America: Taylor \& Francis Group, 2009.

COURA, S. M. C. Mapeamento de vegetação do estado de Minas Gerais utilizando dados MODIS. Dissertação (Mestrado em Sensoriamento Remoto) - Instituto Nacional de Pesquisas Espaciais, São José dos Campos, 2007.

FRANCISCO, C. N.; ALMEIDA, C. M. Avaliação de desempenho de atributos estatísticos e texturais em uma classificação de cobertura da terra baseada em objeto. Boletim de Ciências Geodésicas. Vol.18, n², pp. 302-326. Curitiba - PR. 2012.

HUETE, A. R. LIU, H.Q. BATCHILY, K. VAN LEEUWEN, W. A Comparison of Vegetation Indices over a Global Set of TM Images for EOS-MODIS. Remote sensing of environment, n.59, p.440-451, 1997. 
INPE, INSTITUTO DE PESQUISAS ESPACIAIS. Monitoramento da cobertura florestal da Amazônia por satélites. Sistema PRODES, DETER, DEGRAD e Queimadas 2007-2008. SP: São José dos Campos, 2008a. Disponível em: $<$ http://www.obt.inpe.br/prodes/Relatorio_Prodes2008.pdf>. Acesso em: maio/ 2015.

JIANYA, G.; HAIGANG, S.; GUORUI, M.; QIMING, Z. A Review of MultiTemporal Remote Sensing Data Change Detection Algorithms. The International Archives of the Photogrammetry, Remote Sensing and Spatial Information Sciences, vol. XXXVII, 2008.

LU, D.; MAUSEL, P.; BRONDIZIO, E.; MORAN, E. Change detection techniques. International Journal of Remote Sensing, v. 25 n. 12, pp. 2365-2407, 2004.

MARCUZZO, F. F. N., ROCHA, H. M. MELO, D. C. R. Mapeamento da precipitação pluviométrica no bioma da Amazônia do estado de Mato Grosso. In: X SIMPÓSIO DE RECURSOS HÍDRICOS DO NORDESTE. Anais... Fortaleza, Ceará, 2010.

MORTON, D.; DEFRIES, R. S.; SHIMABUKURO, Y. E.; ANDERSON, L. O.; FERNANDO DEL BON ESPÍRITO-SANTO, F. D. B.; HANSEN, M.; CARROLL, M. Rapid Assessment of Annual Deforestation in the Brazilian Amazon Using MODIS Data. Earth Interactions, vol 9, no. 8, 2005.

PONZONI, F. J.,SHIMABUKURO, Y. E.,KUPLICH, T. M. Sensoriamento Remoto da Vegetação. São Paulo: Oficina de Textos, 2012.90 p.

ROSEMBACK, R. Análise da dinâmica da cobertura vegetal na região sul do brasil a partir de dados MODIS TERRA. Dissertação (Mestrado em Sensoriamento Remoto) - Instituto Nacional de Pesquisas Espaciais, São José dos Campos, 2007.

ROUSE, J.W. HAAS, R.H. SCHELL, J.A. DEERING, D.W. HARLAN, J.C. Monitoring the vernal advancement of retrogradation (greenwave effect) of natural vegetation. NASA/GSFC, Type III, Final Report, Greenbelt, MD, 1974

SEMA/MT, SECRETARIA DE ESTADO DE MEIO AMBIENTE DE MATO GROSSO. Plano de Ação para Prevenção e Controle do Desmatamento e Queimadas do Estado de Mato Grosso. Governo do Estado de Mato Grosso. Cuiabá: SEMA/MT, 2009.

SILVA, E. Território, Cidade e Rede: O Papel de Rondonópolis na Expansão da Soja no Cerrado MatoGrossense. Tese (Doutorado em Geografia Humana) - Universidade de São Paulo. São Paulo: 2009.

SINGH, A. Digital Change Detection techniques using remotely-sensed data. International Journal of Remote Sensing, v. 10 n. 06, pp. 989-1003, 1989. 